\title{
High Myostatin Serum Related with High Prevalence of Sarcopenia Among Elderly Population in Pedawa Village, Bali, Indonesia
}

\author{
I Gusti Putu Suka Aryana ${ }^{1, *}$, I Nyoman Astika ${ }^{1}$, Raden Ayu Tuty Kuswardhani ${ }^{1}$, \\ Ida Bagus Putu Putrawan ${ }^{1}$, Ni Ketut Rai Purnami ${ }^{1}$, Wayan Giri Putra ${ }^{1}$, \\ Anak Agung Wiradewi Lestari ${ }^{2}$, I Nyoman Wande ${ }^{2}$ \\ ${ }^{1}$ Geriatric Division, Department of Internal Medicine, Faculty of Medicine, Universitas Udayana/Sanglah General Hospital Denpasar, Jl. P.B. Sudirman, \\ Denpasar, Bali, Indonesia \\ ${ }^{2}$ Department of Clinical Pathology, Faculty of Medicine, Universitas Udayana/Sanglah General Hospital Denpasar, Jl. P.B. Sudirman, Denpasar, \\ Bali, Indonesia \\ *Corresponding author. E-mail: suka_aryana@unud.ac.id
}

Received date: Apr 16, 2019; Revised date: Jul 19, 2019; Accepted date: Jul 29, 2019

\section{Abstract}

$\mathrm{B}$ ACKGROUND: Sarcopenia is defined as a decrease in muscle mass accompanied by a decrease in muscle strength and performance. Sarcopenia arises from the disruption of the complex balance between anabolic and catabolic factors. Myostatin strongly influences muscle growth inhibition. Deletion and function loss of myostatin causes hyperplasia and skeletal muscle hypertrophy.

METHODS: This study was an analytical cross-sectional study. Seventy respondents aged $\geq 60$ years in Pedawa Village, Bali, Indonesia were selected by using the stratified random sampling technique. Sarcopenia status was assessed according to Asian Working Group for Sarcopenia (AWGS) criteria, including muscle mass, grip strength, and walking speed. While the myostatin serum levels was measured by enzyme-linked immunosorbent assay (ELISA).
RESULTS: The incidence of sarcopenia in the elderly was 45 people (64.3\%). Based on the analysis, there was a significant difference between myostatin levels in sarcopenia subjects (47.59 $\mathrm{ng} / \mathrm{mL})$ and non-sarcopenia subjects $(39.7 \mathrm{ng} / \mathrm{mL})$. Based on the statistical calculations, it was determined that the cut-off range of myostatin levels was $48.91 \mathrm{ng} / \mathrm{mL}$. The prevalence ratio of sarcopenia incidence based on the myostatin levels in the elderly was 3.84, while based on the combination of age risk and myostatin levels was 9.75 .

CONCLUSION: Based of the data, there are significant differences of myostatin level between elderly people with and without sarcopenia. The prevalence of high myostatin levels in elderly is almost 4 times higher than low myostatin levels in the elderly.

KEYWORDS: myostatin, sarcopenia, elderly

Indones Biomed J. 2019; 11(3): 293-8

\section{Introduction}

In various countries, the increasing life expectancy in a sustainable manner has become one humanity's best achievements.(1,2) As a consequence, this also increases the proportion of elderly people. In 2010, there were an estimated 524 million world population aged 65 years or more, which is around $8 \%$ of the world's population.(1)
Aging is related to the progressive change in physiological functions of all organs, which results in morbidity and mortality. $(2,3)$ One of the important change that occurs in old age is a progressive decline in skeletal muscle mass, which in turn leads to sarcopenia, characterized by decrease in muscle mass accompanied by a decrease in muscle strength and function. This causes disability in the elderly to even cause death.(4) The prevalence of sarcopenia increases with age, with the prevalence of sarcopenia at 
age 65 to 70 years between $13 \%$ to $24 \%$ and more than $50 \%$ at the age of more than 80 years.(5) Sarcopenia has implications for skeletal muscle performance, advanced physical and metabolic functions, thus posing a threat real in the health and economic fields. Sarcopenia is thought to arise due to various factors, namely changes in age-related hormones, steroids, sex, physical inactivity, and comorbid conditions such as heart failure, cancer, and diabetes.(6) Recent developments prove the striated muscle produces various cytokines and peptides known as myokine. Myokines as cytokines and peptides are produced, excreted, and released by muscles. Myokine appears as a challenge in the future as an attempt to identify biological mechanisms and determine therapeutic targets to prevent, delay, or cure the condition of sarcopenia. In the context of this molecular causation, growth and differentiation factor (GDF) 8 or myostatin gets attention to be investigated regarding its function as a negative regulator of muscle.(6) Myostatin is part of the superfamily transforming growth factor- $\beta$. The amount is abundant in skeletal muscles, but is also found in lesser amounts in adipose tissue and heart muscle. Delivery of myostatin signals occurs via type IIB activin receptors (ActRIIB), which form a heterodimer with activin-like (ALK)4 or ALK5. Furthermore, the formation of Sma and Mad (SMAD)4 occurs from SMAD2 and SMAD3 phosphorylation with the heterodimer. The complex undergoes translocation to the nucleus and then functions in the proliferation and differentiation of skeletal muscle precursor cells, and the myofiber protein degradation pathway.(7-9) In addition, there is inhibition of action/mammary target of rapamycin (mTOR).(10) As a result of myostatin's activity in regulating cell growth, differentiation, and the pathways for delivering anabolic and catabolic signals, myostatin strongly influences muscle growth and post natal growth. Deletion and loss of function of myostatin causes skeletal muscle hyperplasia and hypertrophy.(6)

Therefore the researchers intend to examine the relationship of myostatin with sarcopenia in elderly. The results of this study are expected to be a reference in future research to prevent and treat sarcopenia

\section{Methods}

\section{Research Design and Sample}

This study was an analytical cross-sectional study The research was conducted in Pedawa Village, Buleleng Regency, Bali in April to October 2018. The sample used in this study were seventy elderly people with age more than or equal to 60 years old and chosen by stratified random sampling. The exclusion criteria from this study were patients with acute infection, malignancy, taking aspirin or nonsteroidal anti-inflammatory drugs (NSAIDs) and corticosteroids for at least the last 2 weeks.

Data were collected by anthropometric measurements, muscle mass, grip strength, walking speed, and measurement of myostatin levels. Ethical permission was obtained from the Ethics Committee of the Research and Development Unit, Faculty of Medicine, Udayana University / Sanglah General Hospital with letter number: 1814/UN.14.2/ Litbang/201.

\section{Anthropometry and Body Fat Percentage}

Anthropometric measurements were carried out by measuring body weight and height. Measurement of height $(\mathrm{cm})$ in the elderly based on knee height converted through the calculation of the Chumlea knee height formula.(11) The waist and hip circumference were measured in centimeters $(\mathrm{cm})$, while the body mass index (BMI) was measured using bioimpedance analysis (BIA), which then categorized into three groups, namely thin $\left(\mathrm{BMI}<18.5 \mathrm{~kg} / \mathrm{m}^{2}\right)$, normal $\left(\mathrm{BMI}=18.5-24.9 \mathrm{~kg} / \mathrm{m}^{2}\right)$, fat and obesity $\left(\mathrm{BMI}>25 \mathrm{~kg} / \mathrm{m}^{2}\right)$. The percentage of body fat was measured by BIA.

\section{Parameters of Sarcopenia}

Based on the recommendations of the Asian Working Group for Sarcopenia (AWGS), the parameters of sarcopenia measured were muscle mass, grip strength, and walking speed.(12) Muscle mass measurements was done using BIA, which obtained skeletal muscle mass (upper limb muscle mass, lower limbs and trunk) with sceletal muscle index $<7.0 \mathrm{~kg} / \mathrm{m}^{2}$ in men and $<5.7 \mathrm{~kg} / \mathrm{m}^{2}$ in women classified as the low muscle mass. Grip strength examinations (muscle strength) were carried out with a handheld dynamometer, expressed in kilograms $(\mathrm{kg})$ with grip strength $<26 \mathrm{~kg}$ for men and $<18 \mathrm{~kg}$ for women classified as low grip strength. The walking speed $(\mathrm{m} / \mathrm{s})$ was calculated by measuring 4.57 meters walking speed with $<0.8 \mathrm{~m} / \mathrm{s}$ defined as a low walking speed. Meanwhile the sarcopenia status was classified into three group, namely pre-sarcopenia, sarcopenia and severe sarcopenia. Pre-sarcopenia was defined by the presence of low muscle mass without low grip strength and low walking speed, sarcopenia was defined by the presence of low muscle mass with one of low grip strength or low walking speed, and severe sarcopenia was defined by the presence three criteria, low muscle mass, low grip strength and low walking speed. 
Table 1. Characteristics of the research samples.

\begin{tabular}{lcc}
\hline \multicolumn{1}{c}{ Variable } & Value & p -value \\
\hline Age (years) & $69.40 \pm 8.31$ & 0.001 \\
Body Mass Index $\left(\mathrm{kg} / \mathrm{m}^{2}\right)$ & $21.48 \pm 4.67$ & 0.022 \\
Body height based on knee height (cm) & $161.57 \pm 6.37$ & 0.200 \\
Body weight (kg) & $50.00 \pm 11.73$ & 0.065 \\
Hip circumference (cm) & $86.58 \pm 13.56$ & 0.000 \\
Upper arm circumference & $25.00 \pm 3.67$ & 0.200 \\
Body fat (\%) & $27.80 \pm 7.67$ & 0.200 \\
Visceral fat (\%) & $7.54 \pm 6.00$ & 0.000 \\
Total skeletal muscle mass (\%) & $90.15 \pm 14.21$ & 0.085 \\
$\quad$ Upper leg muscle mass (\%) & $30.49 \pm 5.83$ & 0.003 \\
$\quad$ Lower leg muscle mass (\%) & $39.15 \pm 6.09$ & 0.001 \\
$\quad$ Trunk muscle mass (\%) & $19.10 \pm 3.72$ & 0.200 \\
Grip strength (kg) & $19.24 \pm 6.83$ & 0.027 \\
Walking speed (m/s) & $0.54 \pm 0.17$ & 0.000 \\
Myostatin (ng/mL) & $42.33 \pm 1.52$ & 0.200 \\
\hline
\end{tabular}

\section{Myostatin Level}

Myostatin levels were examined from blood serum. About $5 \mathrm{~mL}$ of subject venous blood was taken by the researcher. This procedure was carried out by a professional who meets the requirements in the morning (8:00 to 10:00) to avoid the influence of changes in the circadian cycle. Myostatin levels were analyzed using the Quantikine HS Human Myostatin Immonoassay reagent (Catalogue \#DGDF80, R\&D Systems, Minneapolis, USA) measured by the enzyme-linked immunosorbent assay (ELISA) method with the units of $\mathrm{pg} / \mathrm{mL}$.

\section{Data Analysis}

Data analysis was done by using statistical tools SPSS version 16.0 (SPSS Inc, Chicago, USA). Descriptive statistical analysis was done to measure the central tendency (mean and median) and variability (range and standard devision). The independent t-test was applied to compare the myostatin levels among groups, with significancy level $p<0.05$. Calculation of prevalence ratio was done by using $2 \times 2$ tables.

\section{Results}

\section{Characteristics of The Research Sample}

A total of 70 elderlies participated in this study. Male samples were $35(50 \%)$, while female samples were 35 $(50 \%)$. Based on the BMI value, as many as 19 people
(27.1\%) were classified as thin, 37 people $(52.9 \%)$ were classified as normal, and 16 people (20\%) were classified as obese. Table 1 illustrates the characteristics of the research sample.

\section{Prevalence of Sarcopenia}

The status of sarcopenia is known through sarcopenia parameters which were consisting of muscle mass, muscle strength and physical performance. From 70 samples, it was known that 47 people $(67.1 \%)$ had low muscle mass, 49 people $(70 \%)$ had low muscle strength, and 65 people $(92.9 \%)$ had low physical performance. Based on these parameters, the classification of sarcopenia status can be seen in Table 2.

In sarcopenia group, there were more female $(55.6 \%)$ than male $(44.4 \%)$ while in the non sarcopenia group, there were more male $(60 \%)$ than female $(40 \%)$. In the sarcopenia group, $60 \%$ were $\geq 70$ years old whereas in the non sarcopenia group there were more subjects under 70 years old (64\%). (Table 3).

Table 2. Distribution of sarcopenia.

\begin{tabular}{lcc}
\hline Sarcopenia Status & Frequency & Percentage (\%) \\
\hline Normal & 23 & 32.9 \\
Pre-sarcopenia & 2 & 2.9 \\
Sarcopenia & 9 & 12.9 \\
Severe sarcopenia & 36 & 51.4 \\
\hline
\end{tabular}


Table 3. Distribution of sarcopenia based on gender and age group.

\begin{tabular}{lcc}
\hline \multirow{2}{*}{ Characteristic } & \multicolumn{2}{c}{ Sarcopenia Status } \\
\cline { 2 - 3 } & $\begin{array}{c}\text { Sarcopenia } \\
(\mathbf{n = 4 5 )}\end{array}$ & $\begin{array}{c}\text { Non-Sarcopenia } \\
(\mathbf{n}=\mathbf{2 5})\end{array}$ \\
\hline Gender & & \\
Male & $20(44.4 \%)$ & $15(60 \%)$ \\
Female & $25(55.6 \%)$ & $10(40 \%)$ \\
\hline Age & & $16(64 \%)$ \\
$<70$ years old & $18(40 \%)$ & $9(36 \%)$ \\
$\geq 70$ years old & $27(60 \%)$ & \\
\hline
\end{tabular}

\section{Relationship between Myostatin and Sarcopenia Parameters}

T-test was conducted to determine the difference in mean myostatin levels with sample characteristics, namely gender and age and sarcopenia parameters. Based on the analysis, it was found that there was a significant difference between myostatin levels in sarcopenia $(47.59 \mathrm{ng} / \mathrm{mL})$ and myostatin in non-sarcopenia $(39.7 \mathrm{ng} / \mathrm{mL})(p=0.037 ; 95 \% \mathrm{CI}=-15.29$ - -049). The results of the average difference can be seen in Figure 1.

Receiver operating characteristic (ROC) test was conducted to determine the cut off of the myostatin level range with a specificity of $80 \%$ and a sensitivity of $50 \%$, which was $48.91 \mathrm{pg} / \mathrm{mL}$. High level of myostatin $(\geq 48.91$ $\mathrm{pg} / \mathrm{mL}$ ) was found higher in sarcopenia group compared to non-sarcopenia group. From these results the calculation of the ratio of the prevalence of sarcopenia according to myostatin levels in the elderly was 3.83 (Table 4). It means that high myostatin levels have a prevalence 3.83 times higher than low myostatin levels.

The calculation of other sarcopenia risk factors, namely the age category and myostatin level was carried out to determine the effect of the combination of these risk factors. Based on the analysis, risk group was found higher in sarcopenia group compared to non-sarcopenia group. The ratio of the prevalence of sarcopenia based on age risk factors and myostatin levels was 9.75, that means subject with risks have higher prevalence of sarcopenia (Table 5).

\section{Discussion}

This study shows a considerable prevalence of sarcopenia of $64.3 \%$ (12.9\% sarcopenia and $51.4 \%$ severe sarcopenia). This prevalence rate of this study is higher than other studies in Indonesia. A research in Bandung, Indonesia showed that the rate was 9.1\%.(13) Research in the Asian region also found that the average prevalence of sarcopenia in the elderly was around $0.1 \%$ to $56.7 \%$.(14) The magnitude of the sarcopenia prevalence rate in elderly age in Pedawa village, Bali illustrates the condition of the elderly population in populations isolated from outside environmental influences. This study shows prevalence of sarcopenia is more higher

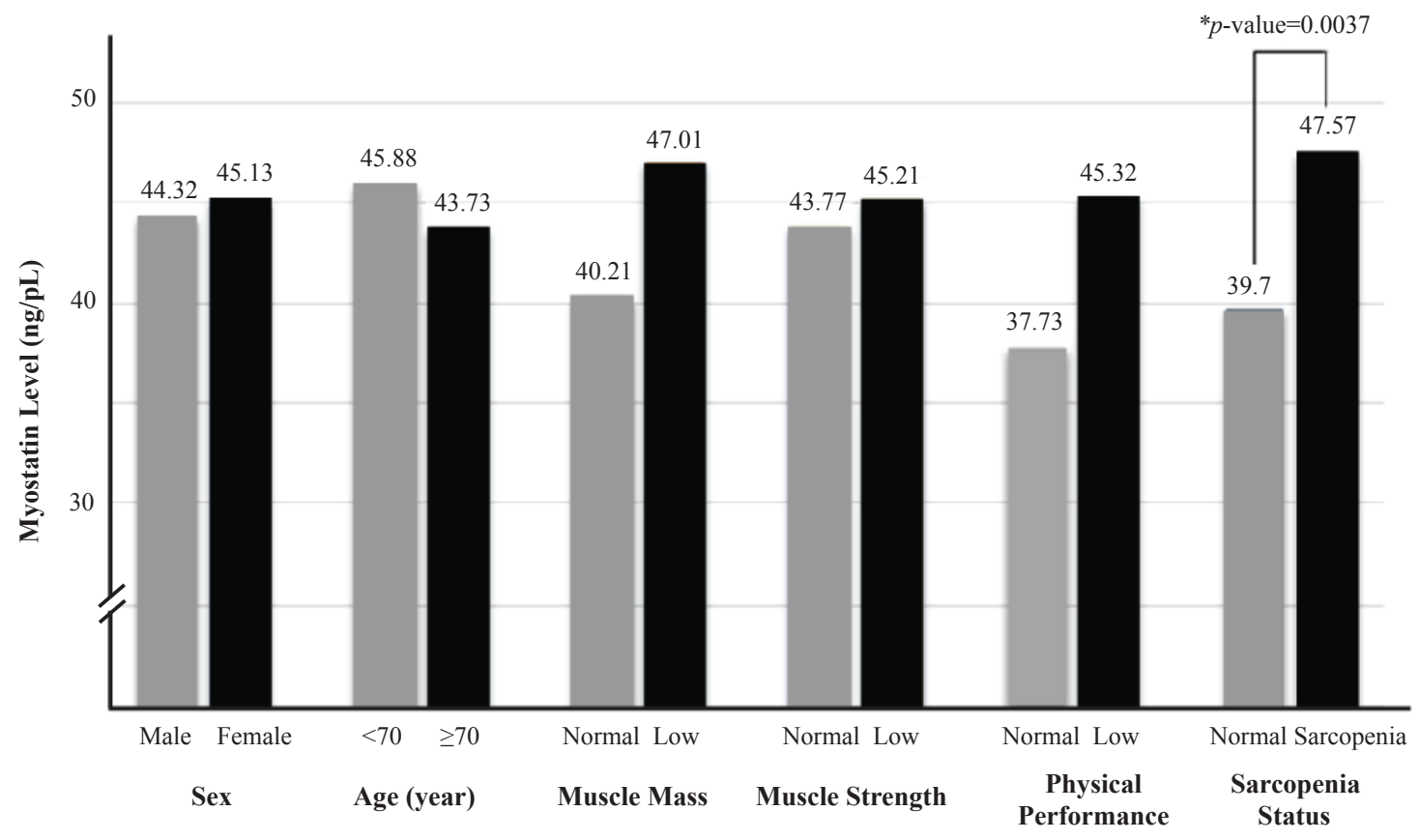

Figure 1. Mean difference of myostatin level with characteristics and parameters of sarcopenia. 
Table 4. Analysis of the effect of myostatin levels on sarcopenia parameters.

\begin{tabular}{lcccc}
\hline \multirow{2}{*}{$\begin{array}{c}\text { Level of } \\
\text { Myostatin }\end{array}$} & \multicolumn{2}{c}{ Sarcopenia Status } & \multirow{2}{*}{ PR $^{*}$} & 95\% CI $^{* *}$ \\
\cline { 2 - 3 } High & Sarcopenia & Non- Sarcopenia & & \\
Low & $22(81.5 \%)$ & $5(18.5 \%)$ & 3.83 & $1.22-11.98$ \\
\hline Total & $23(53.5 \%)$ & $20(46.5 \%)$ & & \\
\hline
\end{tabular}

$* \mathrm{PR}=$ Prevalence ratio; $*$ $* \mathrm{I}=$ Confidence interval.

in female $(55.6 \%)$ than male. These results are similar with the research conducted in western China, whereas most female had sarcopenia compared to male by $12 \%$.(15) This phenomenon can be caused by decreasing estrogen hormone in the elderly, especially at menopause which causes a decrease in bone density and muscle mass. This explains the role of hormones as a risk factor for sarcopenia. (16) Insulin-like growth factor-1 (IGF-1) also decrease after menopause in elderly women. Estrogen and IGF-1 are responsible for activating estrogen receptors. Estrogen receptors have an important role in muscle strength through the anabolic pathway and activating satellite cells. A decrease in estrogen and IGF-1 can cause elderly women loses muscle mass and muscle strength.(17)

This study found $60 \%$ elderly in the sarcopenia group were $\geq 70$ years old. Age affects the occurrence of sarcopenia. The prevalence of sarcopenia increases with age, even more than $40 \%$ of people aged 80 years experience sarcopenia. (18) The aging process naturally affects muscle mass and muscle strength. Muscle mass and muscle strength decrease with age and muscle mass can decrease by $3 \%$ per year after age 60 years.(19)

Comparative analysis showed a significant mean difference of myostatin level between sarcopenia and non-sarcopenia group $(p=0.037 ; 95 \% \mathrm{CI}=-15.29-$-049). Other studies show similar results, where myostatin and sarcopenia are related. A study conducted previously showed that myostatin contributed to an increase in the prevalence of saropenia in women.(20) Another study using mice as the object of the study also showed a link between the absence of myostatin and a decrease in the incidence of sarcopenia.(21) Another study in old rats showed the role of anti-myostatin antibodies in increasing muscle mass and strength.(22) A cohort study in Taiwan with 1839 samples aged 53 to 92 years showed that in the elderly with low myostatin levels had higher risk of having a low skeletal muscle mass compared to the elderly with high myostatin levels $(\mathrm{OR}=3.23$; 95\% $\mathrm{CI}=1.49-7.01)$.(23)

In this study, the cut-off value of myostatin level is $48.91 \mathrm{pg} / \mathrm{mL}$. Based on it, $81.5 \%$ elderly with sarcopenia have myostatin level $\geq 48.91 \mathrm{pg} / \mathrm{mL}$. A cohort study also showed the similar results that myostatin levels in low muscle mass $(47.01 \mathrm{ng} / \mathrm{pL})$ was higher than normal muscle mass $(40.21 \mathrm{ng} / \mathrm{pL})$ and myostatin levels at low physical performance $(45.32 \mathrm{ng} / \mathrm{pL})$ was higher compared to normal physical performance (37.73 ng/pL).(23) The influence of myostatin levels on the incidence of sarcopenia has a $\mathrm{PR}=3.83$, which means that high levels of myostatin have a prevalence of sarcopenia almost 4 times higher than low levels of myostatin in the elderly. Whereas after calculating the combination of risk factors for age and myostatin levels, the prevalence ratio was 9.75 . These results indicate an increase in the ratio of the prevalence of sarcopenia 2.5 times compared to only having a risk of myostatin levels.

Myostatin's performance on the incidence of sarcopenia through the myostatid-smad pathway inhibits

Table 5. Analysis of the effect of risk based on age group and myostatin level on sarcopenia parameters.

\begin{tabular}{|c|c|c|c|c|}
\hline \multirow{2}{*}{$\begin{array}{l}\text { Risks Based on } \\
\text { Age Group and } \\
\text { Myostatin Level }\end{array}$} & \multicolumn{2}{|c|}{ Sarcopenia Status } & \multirow{2}{*}{ PR* } & \multirow{2}{*}{$95 \% C I^{* *}$} \\
\hline & Sarcopenia & Non-Sarcopenia & & \\
\hline Risk & $13(92.9 \%)$ & $1(7.1 \%)$ & 9.75 & $1.19-79.75$ \\
\hline Non-risk & $32(57.1 \%)$ & $24(42.9 \%)$ & & \\
\hline Total & $45(64.3 \%)$ & $25(35.7 \%)$ & & \\
\hline
\end{tabular}

$* \mathrm{PR}=$ Prevalence ratio $; *$ CI $=$ Confidence interval. 
mTOR in response to growth supporting signals (such as insulin and IGF-1). Under normal circumstances, IGF-1 and insulin stimulate protein synthesis through activation of the Akt/mTOR/P70s6k pathway and at the same time inhibit forkhead box $\mathrm{O}$ (FoxO) through phosphorylation. In pathological conditions, the phosphorylated does not inhibit FoxO so that FoxO accumulation occurs in the nucleus which then binds to DNA. The bond will induce transcription of E3 ubiquitin ligase. $(24,25)$ through this pathway myostatin involvement in proliferation and differentiation of skeletal muscle precursor cells, and mature myofiber protein degradation pathways.(7-9)

\section{Conclusion}

The incidence of sarcopenia is more common in elderly women with more than 70 years of age. Based on the myostatin level, it was found that there were significant differences between the elderly with sarcopenia and the elderly without sarcopenia. Elderly people with myostatin levels $\geq 48.91 \mathrm{pg} / \mathrm{mL}$ have a prevalence of sarcopenia almost 4 times higher than elderly with myostatin levels $<48.91$ $\mathrm{pg} / \mathrm{mL}$. Based on a combination of risk factors for age and myostatin levels there was an increase in the prevalence ratio of sarcopenia 2.5 times compared to only having a risk of myostatin levels. Myostatin can be considered for further investigation in an effort to be the target of sarcopenia preventive and curative therapy.

\section{References}

1. National Institute on Aging, National Institutes of Health, US Department of Health and Human Services. Global Health and Aging. Geneva: World Health Organization; 2011.

2. Kirkwood TBL. A systematic look at an old problem. Nature. 2008; 451: 644-7.

3. Arnold A, Egger A, Handschin C. PGC-1 $\alpha$ and myokines in the aging muscle - a mini-review. Gerontology. 2011; 57: 37-43.

4. Cruz-Jentoft AJ, Baeyens JP, Bauer JM, Boirie Y, Cederholm T, Landi F, et al. Sarcopenia: European consensus on definition and diagnosis. Age Ageing. 2010; 39: 412-23.

5. Kim T, Choi KM. Sarcopenia: definition, epidemiology, and pathophysiology. J Bone Metab. 2013; 20: 1-10. doi: 10.11005/ jbm.2013.20.1.1.

6. White TA, Lebrasseur K. Myostatin and sarcopenia: opportunities and challenges - a mini-review. Gerontology. 2014; 60(4): 289-93.

7. Langley B, Thomas M, Bishop A, Sharma M, Gilmour S, Kambadur R. Myostatin inhibits myoblast differentiation by down-regulating MyoD expression. J Biol Chem. 2002; 277: 49831-40.
8. Yang W, Zhang Y, Li Y, Wu Z, Zhu D. Myostatin induces cyclin D1 degradation to cause cell cycle arrest through a phosphatidylinositol 3-kinase/AKT/GSK-3 $\beta$ pathway and is antagonized by insulin-like growth factor. J Biol Chem. 2007; 282: 3799-808.

9. Sartori R, Milan G, Patron M, Mammucari C, Blaauw B, Abraham $\mathrm{R}$, et al. Smad2 and 3 transcription factors control muscle mass in adulthood. Am J Physiol Cell Physiol. 2009; 296: C1248-57.

10. Trendelenburg AU, Meyer A, Rohner D, Boyle J, Hatakeyama S, Glass DJ. Myostatin reduces Akt/TORC1/p70S6K signaling, inhibiting myoblast differentiation and myotube size. AJP Cell Physiol. 2009; 296: C1258-70.

11. Murbawani EA, Puruhita N, Yudomurti. Tinggi badan yang diukur dan berdasarkan tinggi lutut menggunakan rumus Chumlea pada lansia. Med Med Indones. 2012; 49: 1-6.

12. Chen LK, Liu LK, Woo J, Assantachai P, Auyeung TW, Bahyah KS, et al. Sarcopenia in Asia: consensus report of the Asian working group for sarcopenia. J Am Med Dir Assoc. 2014; 15: 95-101.

13. Vitriana, Defi IR, Irawan GN, Setiabudiawan B. Prevalensi sarkopenia pada lansia di komunitas (Community Dwelling) berdasarkan dua nilai cut-off parameter diagnosis. Maj Kedokt Bandung. 2016; 48: 164-70.

14. Limpawattana P, Kotruchin P, Pongchaiyakul C. Sarcopenia in Asia. Osteoporos Sarcopenia. 2015; 1: 92-7.

15. Gao L, Jiang J, Yang M, Hao Q, Luo L, Dong B. Prevalence of sarcopenia and associated factors in Chinese community-dwelling elderly: comparison between rural and urban areas. J Am Med Dir Assoc. 2015; 16: 1003.e1-e6.

16. Messier V, Rabasa-lhoret R, Barbat-artigas S, Elisha B, Karelis AD, Aubertin-leheudre M. Menopause and sarcopenia: a potential role for sex hormones. Maturitas. 2011; 68: 331-6.

17. Phillips SK, Rook KM, Siddle NC, Bruce SA, Woledge RC. Muscle weakness in women occurs at an earlier age than in men, but strength is preserved by hormone replacement therapy. Clin Sci. 1993; 84: 95-8.

18. Baumgartner RN, Koehler KM, Gallagher D, Romero L, Heymsfield $\mathrm{SB}$, Ross RR, et al. Epidemiology of sarcopenia among the elderly in New Mexico. Am J Epidemiol. 1998; 147: 755-63.

19. Fried LP, Walston JD, Ferrucci L. Frailty. In: Geriatric Medicine. 6th ed. Berlin: Springer-Verlag; 2009. p.1067-76.

20. Bergen HR, Farr JN, Vanderboom PM, Atkinson EJ, White TA, Singh $\mathrm{RJ}$, et al. Myostatin as a mediator of sarcopenia versus homeostatic regulator of muscle mass: Insights using a new mass spectrometrybased assay. Skelet Muscle. 2015; 5: 21. doi: 10.1186/s13395-0150047-5.

21. Siriett V, Platt L, Salerno MS, Ling N, Kambadur R, Sharma M. Prolonged absence of myostatin reduces sarcopenia. J Cell Physiol. 2006; 209: 866-73

22. Camporez JG, Petersen MC, Abudukadier A, Moreira G V, Jurczak MJ, Friedman G, et al. Anti-myostatin antibody increases muscle mass and strength and improves insulin sensitivity in old mice. Proc Natl Acad Sci USA.2016; 113: 2212-7.

23. Peng LN, Lee WJ, Liu LK, Lin MH, Chen LK. Healthy communityliving older men differ from women in associations between myostatin levels and skeletal muscle mass. J Cachexia Sarcopenia Muscle. 2018; 9: 635-42.

24. Elkina Y, Haehling S Von, Anker SD. The role of myostatin in muscle wasting: an overview. J Cachexia Sarcopenia Muscle. 2011; 2: $143-51$.

25. Sakuma K, Yamaguchi A. Sarcopenia and age-related endocrine function. Int $\mathrm{J}$ Endocrinol. 2012; 2012: 127362. doi: $10.1155 / 2012 / 127362$. 